\title{
Supported Cu Nanoparticles as Selective and Stable Catalysts for the Gas Phase Hydrogenation of 1,3-Butadiene in Alkene-Rich Feeds
}

Published as part of The Journal of Physical Chemistry virtual special issue "Metal Clusters, Nanoparticles, and the Physical Chemistry of Catalysis".

Giorgio Totarella, Rolf Beerthuis, Nazila Masoud, Catherine Louis, Laurent Delannoy, and Petra E. de Jongh*

Cite This: J. Phys. Chem. C 2021, 125, 366-375

Read Online

\section{ACCESS | Lill Metrics \& More | 回 Article Recommendations | (s) Supporting Information}

ABSTRACT: Supported copper nanoparticles are a promising alternative to supported noble metal catalysts, in particular for the selective gas phase hydrogenation of polyunsaturated molecules. In this article, the catalytic performance of copper nanoparticles ( 3 and $7 \mathrm{~nm}$ ) supported on either silica gel or graphitic carbon is discussed in the selective hydrogenation of 1,3-butadiene in the presence of a 100-fold excess of propene. We demonstrate that the routinely used temperature ramp-up method is not suitable in this case to reliably measure catalyst activity, and we present an alternative measurement method. The catalysts exhibited selectivity to butenes as high as $99 \%$ at nearly complete 1,3-butadiene conversion (95\%). Kinetic analysis showed that the high selectivity can be explained by considering $\mathrm{H}_{2}$ activation as the rate-limiting step and the occurrence of a strong adsorption of 1,3-butadiene with respect to mono-olefins on the $\mathrm{Cu}$ surface. The $7 \mathrm{~nm} \mathrm{Cu}$ nanoparticles on $\mathrm{SiO}_{2}$ were found to be a very stable catalyst, with almost full retention of its initial activity over $60 \mathrm{~h}$ of time on stream at $140{ }^{\circ} \mathrm{C}$. This remarkable long-term stability and high selectivity toward alkenes indicate that $\mathrm{Cu}$ nanoparticles are a promising alternative to replace precious-metal-based catalysts in selective hydrogenation.

\section{INTRODUCTION}

Hydrogenation reactions play a crucial role in fine and bulk chemicals production. A wealth of processes is based on the addition of molecular hydrogen to an unsaturated carboncarbon bond, often using a supported catalyst. Examples include the hydrogenation of polyunsaturated hydrocarbons to olefins, ${ }^{1}$ hardening of vegetable oils, ${ }^{2}$ and selective hydrogenation of various organic compounds such as vitamin intermediates $^{3,4}$ as well as pharmaceutical and agrochemical active ingredients. ${ }^{3,5}$ The selective removal of polyunsaturated hydrocarbons from monounsaturated hydrocarbons is essential for the production of polymer- and synthesis-grade alkenes. $^{1,6-8}$ Polyunsaturated hydrocarbons, which are often present in crude alkene streams (e.g., 1,3-butadiene, up to 1-5 wt $\%$ in $\mathrm{C}_{2}-\mathrm{C}_{4}$ steam cracking mixtures ${ }^{9}$ ), interfere with the subsequent conversion of alkenes as they can degrade polymer quality and/or poison the polymerization catalyst. ${ }^{1,10}$ Consequently, their concentration should be reduced to below tens of ppm. ${ }^{1,10,11}$ This challenge is commonly addressed by selective hydrogenation of the residual polyolefins to the corresponding mono-olefins, commonly using palladium-based

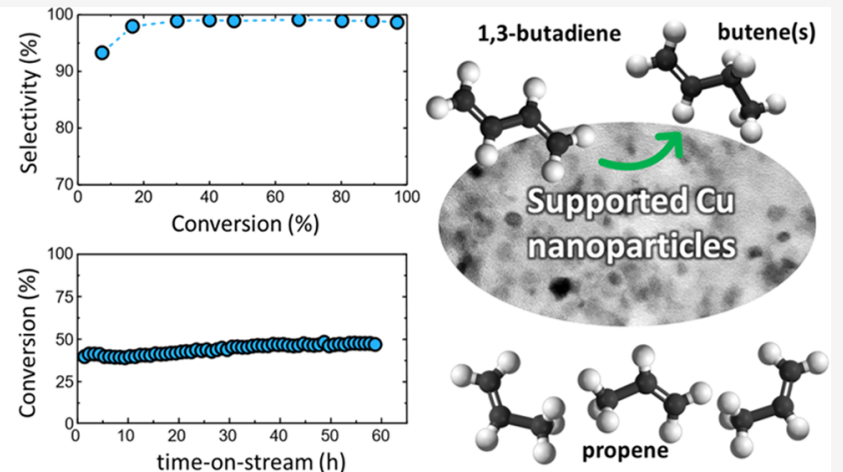

catalysts. ${ }^{12-18} \mathrm{Pd}$ has a very high hydrogenation activity, which can result in a poor selectivity at high alkyne/alkadiene conversion in particular when large $\mathrm{Pd}$ assemblies are present. Therefore, the metal is often diluted or partially deactivated with appropriate modifiers (e.g., $\mathrm{PdAg} / \mathrm{Al}_{2} \mathrm{O}_{3}, \mathrm{PdS} / \mathrm{CaCO}_{3}$, and $\left.\mathrm{PdPb} / \mathrm{CaCO}_{3}{ }^{12,13,15}\right)$. However, restructuring and metal segregation (e.g., when a large excess of diluting metal is present $^{19}$ or after oxidative regeneration of the catalyst ${ }^{20}$ ) can lead to unwanted reactions such as isomerization, polymerization, and over-hydrogenation of the alkenes to alkanes which often results in limited selectivity and decreased catalyst lifetime. $^{19,21}$

The selective hydrogenation of alkynes and alkadienes has generated industrial interest, ${ }^{22-27}$ in particular regarding noble

Received: September 4, 2020

Revised: November 19, 2020

Published: December 23, 2020 
metals catalysis. Nonetheless, little is known about the reaction mechanism, catalyst stability, and selectivity, in particular for the case of more inexpensive and sustainable ${ }^{28}$ catalysts such as those involving base metals. Copper has been reported to be an active catalyst for the selective hydrogenation of alkynes and alkadienes since the 1970s. The reactants investigated were mainly propyne, ${ }^{29} 1,3$-butadiene, ${ }^{30,31} 1$-butyne, ${ }^{8}$ and 1-butene3-yne. ${ }^{8}$ The catalysts were prepared by reduction of precipitated $\mathrm{Cu}$ species ${ }^{8}$ and $\mathrm{Cu}^{2+}$ ion adsorption on silica. ${ }^{32,33}$ Compared to palladium-based catalysts, copper was found to be less active (3-4 orders of magnitude in terms of 1,3butadiene turnover frequency ${ }^{5,34}$ ), but particularly selective, showing almost full conversion to the corresponding alkenes at relatively mild conditions (temperatures below $150{ }^{\circ} \mathrm{C}$ and near-atmospheric pressure $\left.{ }^{8,29,30}\right)$. Unfortunately, the stability of these catalysts was generally poor because of oligomer formation, often termed "green oil formation", which limited further interest in this type of catalyst.

Renewed interest in $\mathrm{Cu}$ as a selective hydrogenation catalyst was spurred by a paper from Studt et al., ${ }^{36}$ who computationally predicted that the best performing metals in the selective hydrogenation of ethyne to ethene share a particularly high adsorption affinity toward the alkyne rather than the alkene. Not only Pd alloys but also base metals and related alloys such as NiZn, FeZn, and monometallic $\mathrm{Ni}$ and $\mathrm{Cu}$ were predicted to be good catalysts. ${ }^{36}$ Recent experimental developments on $\mathrm{Cu}$ based catalysts were reported by the group of Louis et al. ${ }^{35} \mathrm{In}$ particular, the authors showed that the addition of $\mathrm{Zn}$ species to $\mathrm{TiO}_{2}$-supported $\mathrm{Cu}$ catalysts helped to stabilize the catalytic performance. The monometallic copper lost more than $90 \%$ activity within $4 \mathrm{~h}$ on stream, while for the $\mathrm{Cu}_{3} \mathrm{Zn}_{1}$ sample the decrease in activity was limited to $\sim 30 \%$ during $20 \mathrm{~h}$ on stream. Partial alloying of $\mathrm{Zn}$ with $\mathrm{Cu}$ and passivation of $\mathrm{TiO}_{2}$ surface Lewis acid sites by $\mathrm{Zn}$ species might play an important role in stabilizing the samples. ${ }^{35}$ Further insights regarding the support effect on catalyst stability were recently reported by Masoud et al. for Au-based catalysts. ${ }^{37} \mathrm{SiO}_{2}$-supported $\mathrm{Au}$ nanoparticles demonstrated much more stable catalytic performance than $\mathrm{TiO}_{2}$-supported ones (10\% loss of the initial activity for $\mathrm{Au} / \mathrm{SiO}_{2}$ after 5 days on stream at $200{ }^{\circ} \mathrm{C}$, while $\mathrm{Au} / \mathrm{TiO}_{2}$ loses $90 \%$ of its initial activity after $15 \mathrm{~h}$ on stream, same conditions). The steady loss of activity in the case of $\mathrm{Au} / \mathrm{TiO}_{2}$ was due to green oil formation on the surface of the catalyst (around 2 wt \% of carbonaceous deposit, as measured thermogravimetric analysis), and full recovery of the initial catalyst activity was obtained by heating in air. The same amount of carbon deposits was found on bare $\mathrm{TiO}_{2}$ upon exposure to the reaction mixture $\left(16 \mathrm{~h}, 200{ }^{\circ} \mathrm{C}\right),{ }^{37}$ while for $\mathrm{SiO}_{2}$ and $\mathrm{Au} / \mathrm{SiO}_{2}$ the production of those species was negligible. This observation suggests that the formation of oligomers over the $\mathrm{TiO}_{2}$ surface takes place regardless of the type of metal nanoparticles supported on it. ${ }^{37}$

On the basis of these earlier findings, we decided to explore silica- and graphitic carbon-supported copper catalysts for selective hydrogenation. The supports were chosen based on their relative inertness toward oligomer formation (fouling) under reaction conditions. The samples were prepared by means of incipient wetness impregnation. ${ }^{38,39}$ Catalysts were tested in the selective hydrogenation of 1,3-butadiene in an alkene-rich feedstock (1,3-butadiene to propene molar ratio equal to 1 to 100$),{ }^{37,40}$ and we investigated in detail the catalyst selectivity and stability. Attention was also paid to the catalytic testing methodology, which was shown to be of paramount importance to obtain reliable results for copperbased hydrogenation catalysts.

\section{EXPERIMENTAL SECTION}

Details on the chemicals used for the synthesis and gas feeds are reported in the Supporting Information (section 1).

Functionalization of the Carbon Support. The pristine carbon support (HSAG-500, high surface area turbostratic graphitic carbon, average pore size $250 \AA$, BET surface area $500 \mathrm{~m}^{2} \mathrm{~g}^{-1}$; kindly provided by Timcal Ltd.) was surface functionalized by liquid-phase oxidation using concentrated nitric acid. ${ }^{41}$ Herein, $\sim 10 \mathrm{~g}$ of the pristine carbon material was suspended in $\mathrm{HNO}_{3}(\mathrm{aq})\left(65 \%, 40 \mathrm{~mL} \mathrm{~g}^{-1}\right)$ inside a $1 \mathrm{~L}$ roundbottom flask fitted with a reflux condenser. The pristine graphite material was heated to $80{ }^{\circ} \mathrm{C}$ in $\sim 25 \mathrm{~min}$ and kept at $80{ }^{\circ} \mathrm{C}$ for $110 \mathrm{~min}$. Thereafter, the reaction was quenched by diluting the suspensions with $\sim 1.6 \mathrm{~L}$ of cold deionized water $\left(25^{\circ} \mathrm{C}\right)$. The surface-oxidized carbon was allowed to sediment for $30 \mathrm{~min}$, and the supernatants were decanted. The solids were washed with deionized water until a $\mathrm{pH}$ of around 7 was reached. After the final washing step, the carbons were dried overnight at $120{ }^{\circ} \mathrm{C}$ and crushed into powders. Finally, the carbon support was dried for $90 \mathrm{~min}$ at $170{ }^{\circ} \mathrm{C}$, under dynamic vacuum, to remove traces of adsorbed water and kept inside an Ar-filled glovebox (Mbraun LABmaster; <1 ppm of $\mathrm{H}_{2} \mathrm{O}$; $<1$ ppm of $\mathrm{O}_{2}$ ).

Synthesis of $\mathrm{Cu} / \mathrm{SiO}_{2}$. $\mathrm{Cu}$ nanoparticles on silica gel were prepared via adaptation of the impregnation and drying method reported elsewhere for $\mathrm{SiO}_{2}$-based supports. ${ }^{39,42}$ In particular, the impregnation solution concentration and the thermal treatment conditions were adjusted to obtain particles of $\sim 3$ and $\sim 7 \mathrm{~nm}$ (final $\mathrm{Cu}$ weight loading equal to $5.7 \mathrm{wt} \%$ ). Around $2 \mathrm{~g}$ of bare support (Davisil Grade 645, $\geq 99 \%$ purity, average pore size $150 \AA$, BET surface area $300 \mathrm{~m}^{2} \mathrm{~g}^{-1}$; SigmaAldrich) was dried at $230{ }^{\circ} \mathrm{C}$ for $2 \mathrm{~h}$ in a double-neck roundbottom flask. The material was then impregnated under static vacuum with dropwise addition of a $1 \mathrm{M} \mathrm{Cu}\left(\mathrm{NO}_{3}\right)_{2}$ solution acidified to $\mathrm{pH} \sim 1$ with $\mathrm{HNO}_{3}$ to incipient wetness (the volume of the solution used was equal to $90 \%$ of the total pore volume of the support). The impregnated solid was then transferred in a 4A zeolite-filled desiccator and kept there for 2 days. Subsequently, it was further dried under dynamic vacuum at room temperature (RT) for 5 days and then transferred to a tubular plug flow reactor for the final thermal decomposition treatment. Nanosized $\mathrm{Cu}^{0}$ particles of $3 \mathrm{~nm}$ (sample $3 \mathrm{~nm} \mathrm{Cu}$ / $\mathrm{SiO}_{2}$ ) were obtained by heating the solid to $250{ }^{\circ} \mathrm{C}$ under $20 \%$ $\mathrm{H}_{2} / \mathrm{N}_{2}$. The sample was left to cool to RT, purged with $20 \mathrm{vol}$

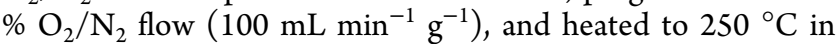
the same gas mixture (heating ramp of $2{ }^{\circ} \mathrm{C} \mathrm{min}{ }^{-1}$, isothermal hold of $2 \mathrm{~h}, 100 \mathrm{~mL} \mathrm{m^{-1 }}$ gas flow for each gram of dry material). It was found that particles cannot be grown larger on silica gel by simply increasing the reduction or the nitrate decomposition temperature (see Figure S1). Larger crystallites were thus prepared by using $2 \% \mathrm{NO} / \mathrm{N}_{2}$ as the gaseous atmosphere during the copper nitrate decomposition step, as previously described by Munnik et al. ${ }^{39}$ In particular, particles of around $7 \mathrm{~nm}$ (sample $7 \mathrm{~nm} \_\mathrm{Cu} / \mathrm{SiO}_{2}$ ) were obtained by performing the thermal treatment at $350{ }^{\circ} \mathrm{C}$ under $2 \% \mathrm{NO} / \mathrm{N}_{2}$ (heating ramp of $2{ }^{\circ} \mathrm{C} \mathrm{min}{ }^{-1}$, isothermal hold of $2 \mathrm{~h}, 300 \mathrm{~mL}$ $\mathrm{min}^{-1}$ gas flow for each gram of dry material). The samples (supported $\mathrm{CuO}$ ) were exposed to air and stored in closed vials at RT. 
Synthesis of $\mathrm{Cu} / \mathrm{C}$. $\mathrm{Cu} / \mathrm{C}$ catalysts were prepared with a similar impregnation and drying method. ${ }^{27,41}$ As for $\mathrm{Cu} / \mathrm{SiO}_{2}$, the synthesis parameters were chosen to obtain particles of $\sim 3$ and $\sim 7 \mathrm{~nm}$ and guarantee homogeneous distribution of the $\mathrm{Cu}$ NPs over the surface of the support. For the preparation, around $2 \mathrm{~g}$ of dry oxidized carbon was impregnated by dropwise addition of a $2 \mathrm{M} \mathrm{Cu}\left(\mathrm{NO}_{3}\right)_{2}$ solution acidified to $\mathrm{pH}$ $\sim 1$ with $\mathrm{HNO}_{3}$ to incipient wetness (the volume of the solution used was equal to $90 \%$ of the total pore volume of the support; resulting $\mathrm{Cu}$ weight loading equal to $6.3 \mathrm{wt} \%)$. The dried impregnate was heated to $230{ }^{\circ} \mathrm{C}\left(0.5{ }^{\circ} \mathrm{C} \mathrm{min}^{-1}\right)$, followed by $1 \mathrm{~h}$ isothermal hold at $230{ }^{\circ} \mathrm{C}$, under $\mathrm{N}_{2}$ flow (100 $\mathrm{mL} \min ^{-1} \mathrm{~g}^{-1}$ ) to decompose the nitrate precursor. The sample was left to cool to $\mathrm{RT}$, purged with 20 vol $\% \mathrm{O}_{2} / \mathrm{N}_{2}$ flow $\left(100 \mathrm{~mL} \mathrm{~min}^{-1} \mathrm{~g}^{-1}\right)$ for $3 \mathrm{~h}$ at RT, and then purged with pure $\mathrm{N}_{2}$ flow $\left(100 \mathrm{~mL} \mathrm{~min} \mathrm{~m}^{-1} \mathrm{~g}^{-1}\right.$ ) for $30 \mathrm{~min}$. Subsequently, the material was reduced by heating to $150{ }^{\circ} \mathrm{C}\left(2{ }^{\circ} \mathrm{C} \mathrm{min}^{-1}\right)$, with $2 \mathrm{~h}$ isothermal hold at $150{ }^{\circ} \mathrm{C}$, under 5 vol $\% \mathrm{H}_{2} / \mathrm{N}_{2}$ flow $\left(100 \mathrm{~mL} \mathrm{~min} \mathrm{~g}^{-1}\right)$. Next, the temperature was increased to either 250 or $400{ }^{\circ} \mathrm{C}\left(2{ }^{\circ} \mathrm{C} \mathrm{min}{ }^{-1}\right)$, with $1 \mathrm{~h}$ isothermal hold at the final temperature, to obtain the $3 \mathrm{~nm} \mathrm{Cu} / \mathrm{C}$ and $7 \mathrm{~nm} \mathrm{Cu}$ / $\mathrm{C}$ catalysts, respectively. The final catalyst was collected after letting it cool to RT and passivating it by exposure to air (overnight) at RT and then stored in closed vials at RT. Prior to X-ray powder diffraction analysis and TEM imaging, the nanoparticles were fully oxidized under 20 vol $\% \mathrm{O}_{2} / \mathrm{N}_{2}$ flow $\left(100 \mathrm{~mL} \mathrm{~min}^{-1} \mathrm{~g}^{-1}\right)$ at $250{ }^{\circ} \mathrm{C}$ (heating ramp of $2{ }^{\circ} \mathrm{C} \mathrm{min}^{-1}$, isothermal hold of $2 \mathrm{~h}$ ).

X-ray Powder Diffraction (XRD) and TEM Imaging. Characterization measurements were performed on XRD analysis was performed on the as-prepared samples with a Bruker D2 Phaser. Radiation source: Co K $\alpha$ (1.78897 $\AA)$. The diffractogram were recorded in the $2 \theta$ interval $15^{\circ}-90^{\circ}$ with a step size of $0.05^{\circ}$. Rietveld refinement was performed with DIFFRAC.SUITE TOPAS software. Transmission electron micrographs of the $\mathrm{Cu} / \mathrm{C}$ and $\mathrm{Cu} / \mathrm{SiO}_{2}$ catalysts were obtained on a Tecnai F20 apparatus, operated at $200 \mathrm{kV}$. Scanning transmission electron microscopy was performed in high-angle annular dark-field (HAADF) mode on a Talos F200X (FEI), equipped with a high-brightness field emission gun (X-FEG) and operated at $200 \mathrm{kV}$. Prior to TEM imaging, the two silicasupported samples were both ultramicrotomed to increase the contrast between the amorphous silica gel support and the $\mathrm{Cu}$ nanoparticles. The catalyst grains $(<75 \mu \mathrm{m})$ were embedded in a two-component epoxy resin (Epofix, EMS) and cured at 60 ${ }^{\circ} \mathrm{C}$ for $24 \mathrm{~h}$. The embedded catalysts were sliced into $50 \mathrm{~nm}$ nominal thickness sections by means of a Diatome Ultra $35^{\circ}$ diamond knife mounted on a Reichert-Jung Ultracut E microtome. The sections were then deposited on a TEM grid and analyzed. Graphitic carbon supported materials were finely grinded via mortar and pestle and dry deposited onto the TEM grids. Average particle sizes are defined as $d_{\mathrm{TEM}}=$ $\sum_{i}\left(d_{\mathrm{NP}, i}{ }^{3} / d_{\mathrm{NP}, i}{ }^{2}\right)$, while particle size dispersion was described as the standard deviation. The number of surface copper atoms was calculated by using a copper dispersion of $1.46 \times 10^{19}$ atoms per square meter of $\mathrm{Cu}$ exposed surface area. We calculated the latter by assuming a spherical particle shape and using the equation $S_{\mathrm{Cu}}=6000 / d_{\mathrm{TEM}} \rho_{\mathrm{Cu}}$, where $S_{\mathrm{Cu}}$ is the specific copper surface area $\left(\mathrm{m}_{\mathrm{Cu}}{ }^{2} \mathrm{~g}_{\mathrm{Cu}}{ }^{-1}\right), d_{\mathrm{TEM}}$ is the mean particle diameter, and $\rho_{\mathrm{Cu}}$ is the copper density (8.92 $\mathrm{g}$ $\mathrm{cm}^{-3}$ ). ${ }^{39}$ The $\mathrm{CuO}$ and $\mathrm{Cu}$ particle sizes (after reduction of the precatalyst prior to catalytic tests) were assumed to be the same.
Catalytic Tests. The catalytic tests were performed with the use of a tailor-made gas-phase hydrogenation setup previously described by Masoud et al. ${ }^{37}$ The experiments were performed by loading a homogeneous mixture of each individual sample (sieve fraction $75-150 \mu \mathrm{m}$; total amount of copper loaded in the reactor equal to $1.28 \mathrm{mg}$ ) and $150 \mathrm{mg}$ of $\mathrm{SiC}$ as thermal diluent (sieve fraction $212-425 \mu \mathrm{m}$ ) in a $\mathrm{U}$ shaped Pyrex packed bed microreactor (internal diameter of 4 $\mathrm{mm}$ ). Prior to the test, the catalysts were reduced in situ under pure $\mathrm{H}_{2}$ flow $\left(50 \mathrm{~mL} \mathrm{~min}{ }^{-1}\right.$ ) from $\mathrm{RT}$ to $250{ }^{\circ} \mathrm{C}$ (ramp $2{ }^{\circ} \mathrm{C}$ $\mathrm{min}^{-1}$ ) and kept at $250{ }^{\circ} \mathrm{C}$ for $90 \mathrm{~min}$. Hereafter, the catalyst was put into contact with the reaction mixture $(0.3 \%$ butadiene, $30 \%$ propene, $20 \%$ hydrogen, and helium for

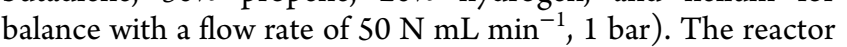
temperature was either linearly increased from RT to $150^{\circ} \mathrm{C}$ at $0.5^{\circ} \mathrm{C} / \mathrm{min}$ or held constant for $2 \mathrm{~h}$ long isothermal steps in the range $110-180^{\circ} \mathrm{C}$. More details on the methodology can be found later in the text (see sections Activity Measured during a Temperature Ramp and Activity under Steady State Conditions). The concentration of the products and unconverted reactants was monitored every $15 \mathrm{~min}$ via gas chromatography by using a flame ionization detector (GCFID; hydrocarbons detected: $\mathrm{C}_{1}-\mathrm{C}_{4}$ ). The composition of the gas mixture fed to the reactor was monitored at the beginning and at the end of each catalytic run by bypassing the reactor bed. Calculated turnover frequencies (TOF, $\mathrm{s}^{-1}$ ) were defined as the molecules of 1,3-butadiene consumed per unit time per $\mathrm{Cu}$ surface atom (see section 4 of the Supporting Information).

\section{RESULTS AND DISCUSSION}

Structural Characterization of $\mathrm{Cu} / \mathrm{C}$ and $\mathrm{Cu} / \mathrm{SiO}_{2}$. The structural properties of the prepared catalysts (oxidized form) were investigated by X-ray powder diffraction, and results are reported in Figure 1. $\mathrm{CuO}$ crystallite sizes obtained via Rietveld refinement are shown in Table 1. Both silicasupported samples $\left(3 \mathrm{~nm} \_\mathrm{Cu} / \mathrm{SiO}_{2}\right.$ and $\left.7 \mathrm{~nm} \_\mathrm{Cu} / \mathrm{SiO}_{2}\right)$ display two main characteristic $\mathrm{CuO}$ reflections peaks at $42^{\circ}$ and $45.5^{\circ}$ (corresponding to the [002] and [111] diffractions,

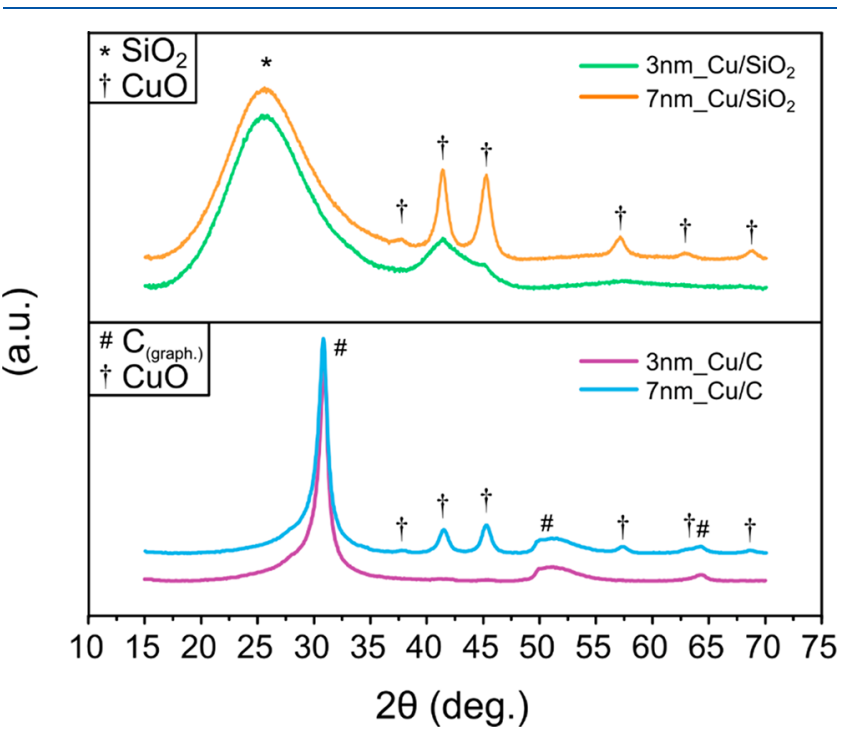

Figure 1. X-ray powder diffraction patterns of the oxidized $3 \mathrm{~nm} \_\mathrm{Cu} /$ $\mathrm{SiO}_{2}, 7 \mathrm{~nm} \_\mathrm{Cu} / \mathrm{SiO}_{2}, 3 \mathrm{~nm} \_\mathrm{Cu} / \mathrm{C}$, and $7 \mathrm{~nm} \_\mathrm{Cu} / \mathrm{C}$. X-ray source: Co $\mathrm{K} \alpha$. 
Table 1. Structural Properties for the As-Prepared Samples

\begin{tabular}{ccccc} 
& & \multicolumn{2}{c}{ particle size } & \\
\cline { 3 - 4 } catalysts & $\begin{array}{c}\mathrm{Cu}^{0} \text { weight } \\
\text { loading } \%)\end{array}$ & $d_{\text {TEM }}(\mathrm{nm})$ & $\begin{array}{c}d_{\text {XRD }} \\
(\mathrm{nm})\end{array}$ & $\begin{array}{c}\mathrm{Cu} \\
\text { dispersion } \\
(\%)\end{array}$ \\
$3 \mathrm{~nm} \_\mathrm{Cu} / \mathrm{SiO}_{2}$ & 5.7 & $3.5 \pm 1.0$ & 3.1 & 20 \\
$7 \mathrm{~nm} \_\mathrm{Cu} / \mathrm{SiO}_{2}$ & 5.7 & $7.3 \pm 2.4$ & 10.4 & 14 \\
$3 \mathrm{~nm} \_\mathrm{Cu} / \mathrm{C}$ & 6.3 & $3.1 \pm 0.9$ & n.a. & 34 \\
$7 \mathrm{~nm}$ _Cu/C & 6.3 & $7.3 \pm 1.8$ & 10.1 & 14 \\
\hline
\end{tabular}

respectively), while the broad scattering band at $25^{\circ}$ is ascribed to the disordered silica gel support. The peak broadening for $3 \mathrm{~nm} \_\mathrm{Cu} / \mathrm{SiO}_{2}$ indicates the presence only small $\mathrm{CuO}$ crystallites in this sample. For $7 \mathrm{~nm} \_\mathrm{Cu} / \mathrm{SiO}_{2}$ the intense and much sharper diffraction peaks demonstrate the presence of large $\mathrm{CuO}$ crystallites. The average $\mathrm{CuO}$ crystallite sizes were found to be 3.1 and $10.4 \mathrm{~nm}$ in $3 \mathrm{~nm} \_\mathrm{Cu} / \mathrm{SiO}_{2}$ and $7 \mathrm{~nm} \_\mathrm{Cu} /$ $\mathrm{SiO}_{2}$, respectively (Table 1 ). The diffractogram of the $3 \mathrm{~nm} \_\mathrm{Cu} / \mathrm{C}$ did not show any $\mathrm{CuO}$ or $\mathrm{Cu} / \mathrm{Cu}_{2} \mathrm{O}$ reflections, implying a high copper dispersion. Lastly, the sample $7 \mathrm{~nm} \_\mathrm{Cu} / \mathrm{C}$ exhibited intense $\mathrm{CuO}$ peaks, and the average crystallite size was found to be $10.1 \mathrm{~nm}$, similar to the $7 \mathrm{~nm} \_\mathrm{Cu} / \mathrm{SiO}_{2}$ sample.

The XRD results show that the crystallite sizes on carbon can be tuned by changing the temperature at which the catalyst is treated. A reduction step performed at $400{ }^{\circ} \mathrm{C}$ led to larger and more crystalline $\mathrm{CuO}$ nanoparticles (sample: $7 \mathrm{~nm} \_\mathrm{Cu}$ / $\mathrm{C}$ ), while at $250{ }^{\circ} \mathrm{C}$ particle growth was limited (sample: $3 \mathrm{~nm} \_\mathrm{Cu} / \mathrm{C}$ ). This was not observed in the case of $\mathrm{CuO}$ over $\mathrm{SiO}_{2}$ (see Figure $\mathrm{S} 1$ ). The difference between carbon and silica supports suggests that $\mathrm{Cu}$ (or $\mathrm{CuO}$ ) particles are much more strongly anchored on the surface of the silica gel rather than on the modified graphitic carbon. Moreover, reduction under $\mathrm{H}_{2}$ at $250{ }^{\circ} \mathrm{C}$ results in visible $\mathrm{CuO}$ particles on $\mathrm{SiO}_{2}$ but not on oxidized carbon by XRD, which may indicate a different interaction of the copper species with these two supports, such as the presence of a nonhomogeneous $\mathrm{CuO}$ phase over the carbon support.

The $\mathrm{CuO}$ nanoparticle sizes and distributions on both silica and surface-oxidized graphitic carbon were investigated with TEM (Figure 2). A uniform distribution of the $\mathrm{CuO}$ particles over the surface of the support was observed for both the silica and the graphitic carbon. Interestingly, the $3 \mathrm{~nm} \_\mathrm{Cu} / \mathrm{C}$ sample contained small particles all over the surface of the carbon, which had been not detected via XRD probably due to low crystallinity. Unimodal particle size distributions were found for all the four samples, and no particles above $20 \mathrm{~nm}$ in diameter were present.

The particle diameters as determined by TEM are in good agreement with the crystallite sizes as determined by XRD (Table 1). In the case of $7 \mathrm{~nm} \_\mathrm{Cu} / \mathrm{C}$ and $7 \mathrm{~nm} \_\mathrm{Cu} / \mathrm{SiO}_{2}, \mathrm{XRD}$ data analysis gives a slightly $\overline{\text { larger crystallite }} \overline{\text { diameter (about }}$ $10 \mathrm{~nm}$ ) in both cases. This could be explained by considering the higher degree of crystallinity and hence diffraction intensity of the larger particles present in those samples (most probably caused by slight overimpregnation of a fraction of the support), which leads to a stronger contribution to the overall signal by the larger crystallites. Hence, the effective copper dispersion used for the evaluation of the catalytic data was based on the $\mathrm{CuO}$ particle sizes determined from TEM data (Table 1).

Activity Measured during a Temperature Ramp. Figure 3A depicts the 1,3-butadiene conversion as a function of the temperature measured while linearly heating the in situ prereduced samples from 50 to $175{ }^{\circ} \mathrm{C}\left(0.5^{\circ} \mathrm{C} \mathrm{min}{ }^{-1}\right)$. All Cucontaining catalysts showed a similar conversion-temperature plot, with an onset temperature around $105{ }^{\circ} \mathrm{C}$, followed by a sharp increase up to full hydrogenation $\left(T_{98 \%}=120-130^{\circ} \mathrm{C}\right)$. The copper catalysts were almost fully selective toward butenes, and the main product was 1-butene (selectivity $\sim 70 \%$, see Figure S2). Smaller amounts of cis-2-butene and trans-2-butene were also detected (10-15\%), and their concentration increased along with the temperature. The selectivity to butane and propene conversion were generally
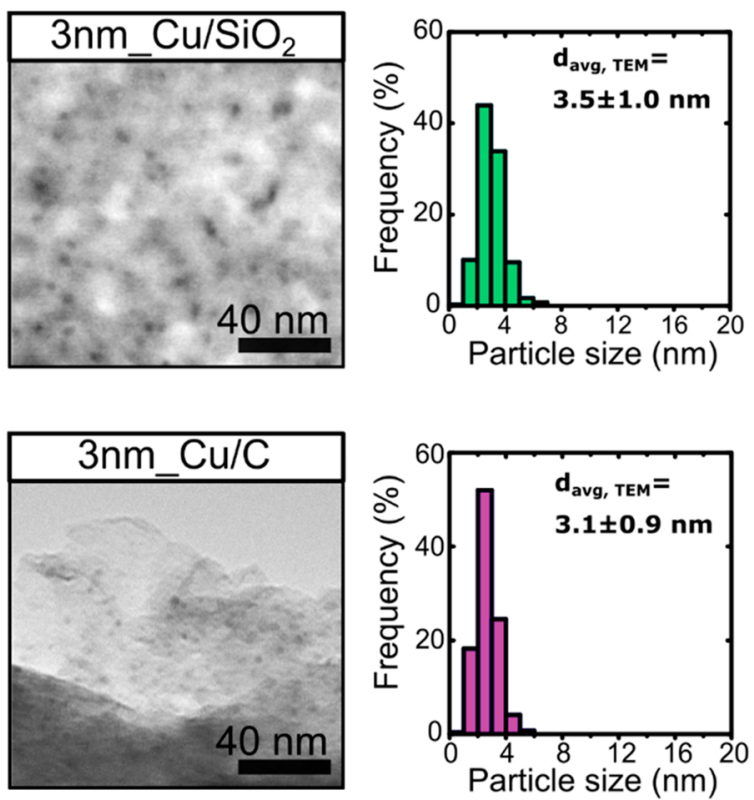
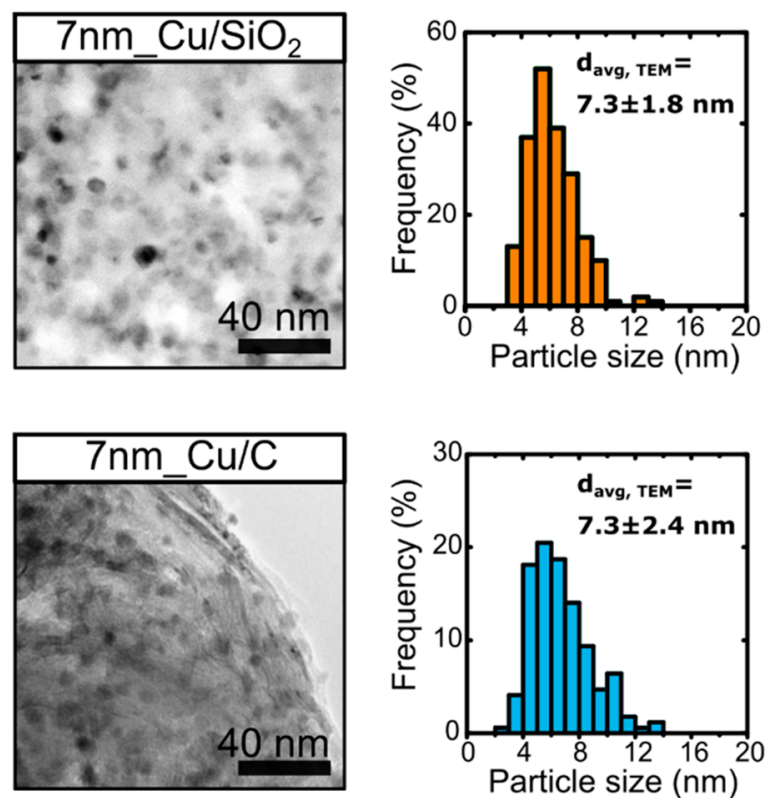

Figure 2. Representative transmission electron micrographs for the as synthesized $3 \mathrm{~nm} \_\mathrm{Cu} / \mathrm{C}, 3 \mathrm{~nm} \_\mathrm{Cu} / \mathrm{SiO}_{2}, 7 \mathrm{~nm} \_\mathrm{Cu} / \mathrm{C}$, and $7 \mathrm{~nm} \_\mathrm{Cu} / \mathrm{SiO}{ }_{2}$ catalysts, with the corresponding particle size distributions. Silica-supported samples were ultramicrotomed to 50 nm slices (nominal thickness) prior to imaging. 

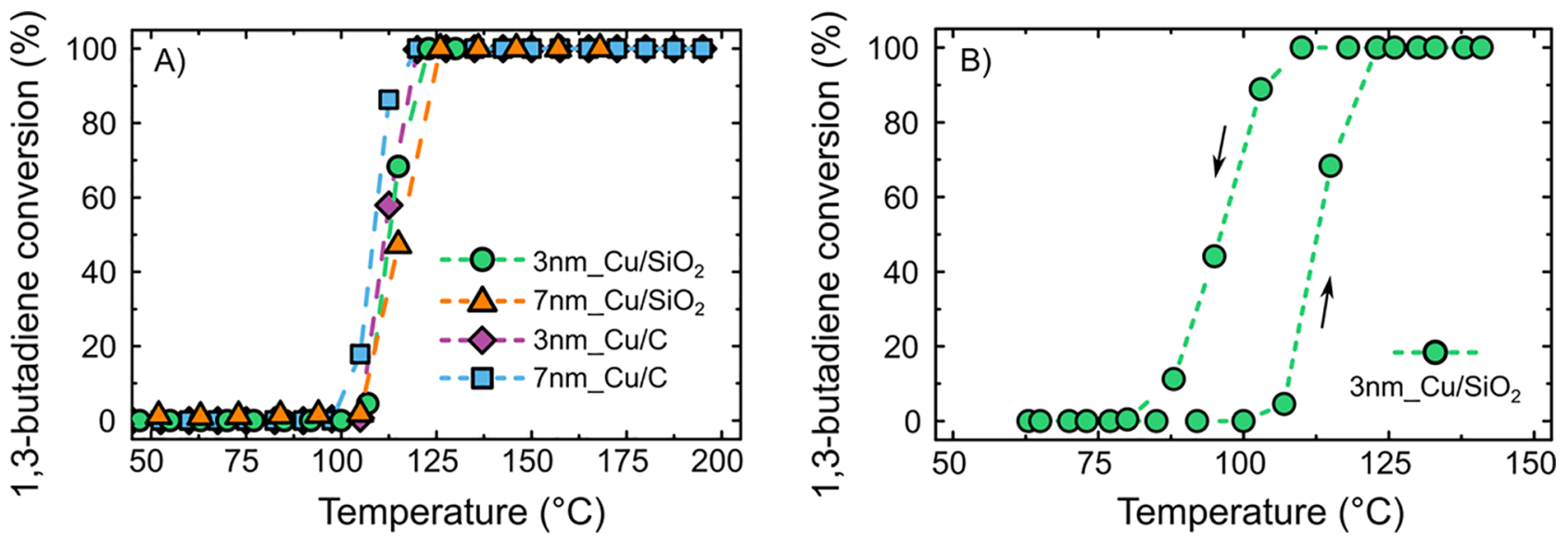

Figure 3. (A) 1,3-Butadiene conversion as a function of temperature for the $3 \mathrm{~nm} \mathrm{Cu} / \mathrm{SiO}_{2}, 7 \mathrm{~nm} \mathrm{Cu} / \mathrm{SiO}_{2}, 3 \mathrm{~nm} \mathrm{Cu} / \mathrm{C}$, and $7 \mathrm{~nm} \mathrm{Cu} / \mathrm{C}$ samples. The data points were collected while heating the prereduced catalyst from 50 to $175{ }^{\circ} \mathrm{C}$ (heating ramp $0 . \overline{5}{ }^{\circ} \mathrm{C} \min ^{-1}$ ). (B) $1,3-B u t a d i e n e$ conversion as a function of the temperature for the sample $3 \mathrm{~nm} \mathrm{Cu} / \mathrm{SiO}_{2}$. The data points were collected while heating the in situ prereduced catalyst from 50 to $175{ }^{\circ} \mathrm{C}$ and then cooling the used catalyst back to RT (temperature ramp: $0.5{ }^{\circ} \mathrm{C} \mathrm{min}^{-1}$ ). Reaction conditions: butadiene/ propene $/ \mathrm{H}_{2} / \mathrm{He}=0.15 / 15 / 10 / 24.85 \mathrm{~mL} \mathrm{~min}^{-1}, 1$ bar absolute pressure and $1.28 \mathrm{mg}$ of Cu loaded. GHSV: $35000 \mathrm{~h}^{-1}$.

below $1.5 \%$ and $1 \%$, respectively, at almost full (>95\%) $1,3-$ butadiene conversion. The bare supports did not show any hydrogenation activity when exposed to the reactant mixture at temperatures up to $200{ }^{\circ} \mathrm{C}$.

All samples seem to have the same activity (per unit $\mathrm{Cu}$ mass) within error at temperatures between 105 and $125^{\circ} \mathrm{C}$. This is surprising as differences due to the different particles sizes and supports might be expected. Hence, we started a more detailed study of the activity by temperature cycling experiments, with as an example results for $3 \mathrm{~nm} \_\mathrm{Cu} / \mathrm{SiO}_{2}$ reported in Figure 3B. A pronounced hysteresis was observed; the high 1,3-butadiene conversion was retained to temperatures below $105{ }^{\circ} \mathrm{C}$ during cooling. A possible explanation might be the formation of local hot spots in the catalyst bed due to the exothermicity of the hydrogenation reaction, although this is not expected under the given conditions (see section 2 of the Supporting Information). Another possibility is that the low activity between 85 and $105{ }^{\circ} \mathrm{C}$ during the first heating ramp is due to deactivation of the surface of the copper nanoparticles by oxidation. Oxidation of copper is favored at low temperatures (e.g., during cooling steps after in situ activation or at the beginning of the catalytic test heating ramp) and can be caused by trace amounts of oxygen and/or water that are always present in commercial gas mixtures. The onset of activity might correspond to the reduction of $\mathrm{Cu}$ oxides by the $\mathrm{H}_{2}$ present in the reaction mixture. This is supported by the fact that indeed the onset of hydrogenation activity shown in Figure 3 is very close to the onset of reduction of $\mathrm{Cu}$ oxides (see Figure S3). Such deactivation by formation of surface oxides, which are reduced at a certain temperature, would also explain the similar activity onset temperatures observed for all catalysts (Figure 3A).

Interestingly, a sudden increase in conversion between 100 and $120{ }^{\circ} \mathrm{C}$ was previously reported also in the case of hydrogenation of various alkynes using $\mathrm{Cu}$-based catalysts. ${ }^{8}$ In fact, using a single heating ramp is a common way to assess the activity of catalysts. Although this might be a valid method when measuring catalytic performance of more noble metals such as $\mathrm{Pd},{ }^{43} \mathrm{Pt},{ }^{44}$ or $\mathrm{Au},{ }^{37,45}$ clearly for Cu-based catalysts the intrinsic properties might be obscured by oxidation. Therefore, another type of testing protocol had to be developed, as described in the next section.
Activity under Steady-State Conditions. The new measurements protocol involved a first step of catalyst preconditioning for $15 \mathrm{~h}$ under reaction mixture at $T=$ $110-130{ }^{\circ} \mathrm{C}$. Subsequently, the catalyst was heated (or cooled) to the desired temperature, and kinetic data were recorded for $2 \mathrm{~h}$ in isothermal conditions. The data points used for performance evaluation were collected at the end of a $2 \mathrm{~h}$ hold to reach a steady state in terms of solid-to-gas interface composition and thermal equilibrium. The process was iterated at each temperature level, and multiple points were collected at one chosen temperature (e.g., $120{ }^{\circ} \mathrm{C}$ for the sample $3 \mathrm{~nm} \_\mathrm{Cu} / \mathrm{SiO}_{2}$, as reported in Figure S4) to detect any deactivation or activation phenomena of the catalyst during the entire duration of the test. As an example, the 1,3-butadiene conversions as a function of the temperature obtained with the described protocol are given in Figure 4A,B for three selected catalysts: $3 \mathrm{~nm} \_\mathrm{Cu} / \mathrm{SiO}_{2}, 7 \mathrm{~nm} \_\mathrm{Cu} / \mathrm{SiO}_{2}$, and $7 \mathrm{~nm} \_\mathrm{Cu} / \mathrm{C}$. With this new measurement protocol, the activity plot looked very different from the one obtained by linearly heating the catalyst (Figure 3): the new protocol yielded a well-defined onset temperature of activity, no hysteresis, and clear differences between the various catalysts. Both $7 \mathrm{~nm} \_\mathrm{Cu} / \mathrm{C}$ and $7 \mathrm{~nm} \_\mathrm{Cu} / \mathrm{SiO}_{2}$ showed very similar conversion profiles (Figure $4 \overline{\mathrm{A}}$ ). Hydrogenation activity was measurable starting at around $115{ }^{\circ} \mathrm{C}$ with almost full 1,3-butadiene conversion reached at around $170{ }^{\circ} \mathrm{C}$. However, the sample $3 \mathrm{~nm} \mathrm{Cu} /$ $\mathrm{SiO}_{2}$ (Figure 4B) displayed a higher activity than the $7 \mathrm{~nm} \_\mathrm{Cu} / \mathrm{SiO}_{2}$, with full hydrogenation at $135^{\circ} \mathrm{C}$.

The turnover frequencies (normalized to the number of exposed copper atoms) measured at $125{ }^{\circ} \mathrm{C}$ were $(6 \pm 2) \times$ $10^{-3},(5 \pm 2) \times 10^{-3}$, and $(22 \pm 6) \times 10^{-3} \mathrm{~s}^{-1}$ respectively for $7 \mathrm{~nm} \_\mathrm{Cu} / \mathrm{C}, 7 \mathrm{~nm} \_\mathrm{Cu} / \mathrm{SiO}_{2}$, and $3 \mathrm{~nm} \_\mathrm{Cu} / \mathrm{SiO}_{2}$. The TOFs measured for $\mathrm{Cu}$ nanoparticles in this work can be compared for those previously reported in the literature. Wang et al. measured a turnover frequency of $32 \times 10^{-3} \mathrm{~s}^{-1}$ at $105^{\circ} \mathrm{C}$ for $5 \mathrm{~nm} \mathrm{Cu}$ on $\mathrm{TiO}_{2}$ (same reaction conditions), ${ }^{46}$ comparable but appreciably higher activity than the catalyst hereby reported. The authors, in fact, stated that the catalyst was able to partially hydrogenate 1,3-butadiene at temperatures as low as $60{ }^{\circ} \mathrm{C} .{ }^{46}$ The lower Cu-based activity for the catalysts supported on $\mathrm{SiO}_{2}$ and carbon, compared to $\mathrm{TiO}_{2}$, may be caused by the presence of support effects for small nano- 

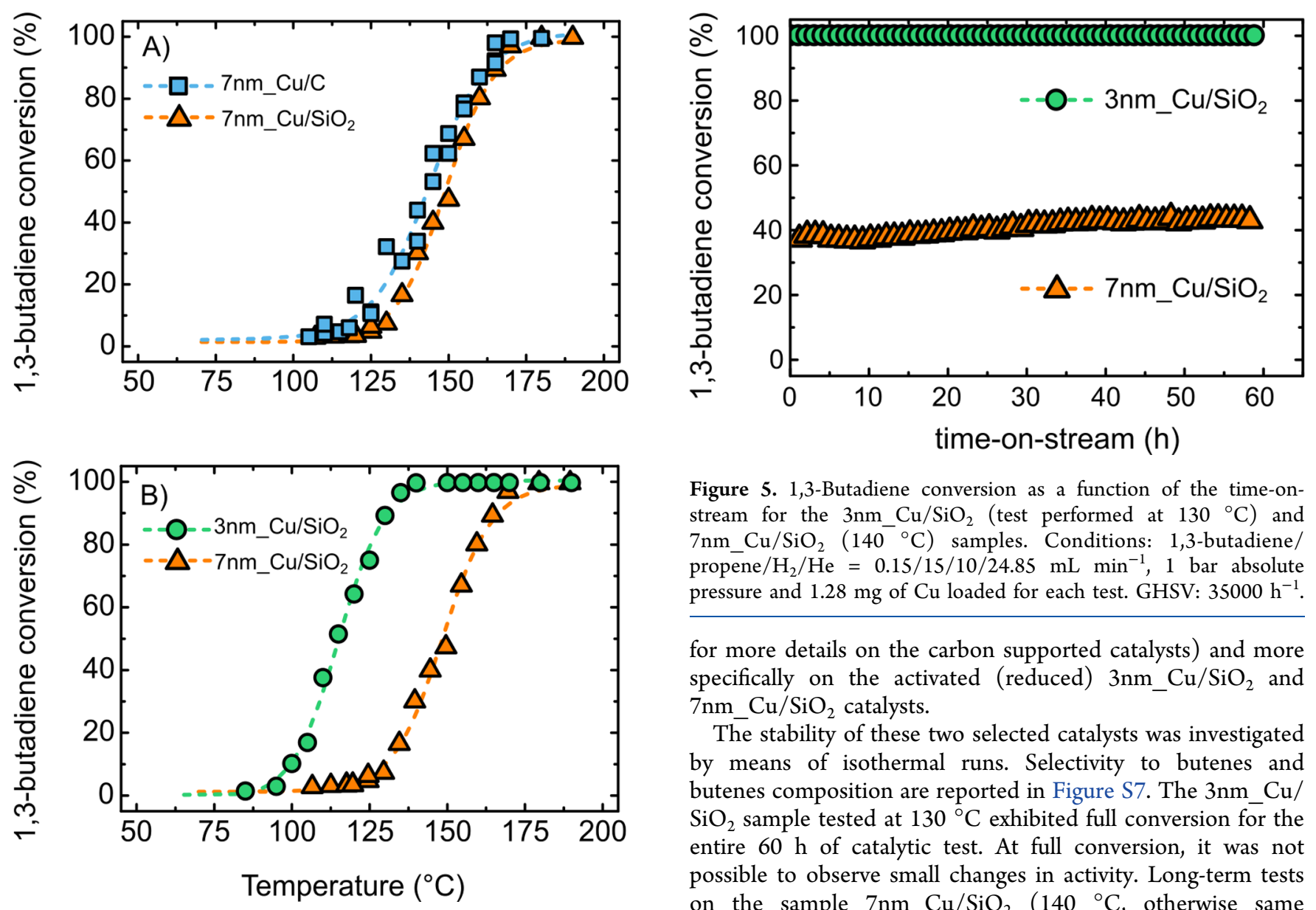

Figure 5. 1,3-Butadiene conversion as a function of the time-onstream for the $3 \mathrm{~nm} \mathrm{Cu} / \mathrm{SiO}_{2}$ (test performed at $130{ }^{\circ} \mathrm{C}$ ) and $7 \mathrm{~nm} \_\mathrm{Cu} / \mathrm{SiO}_{2}\left(140^{\circ} \mathrm{C}\right)$ samples. Conditions: 1,3-butadiene/ propene $/ \mathrm{H}_{2} / \mathrm{He}=0.15 / 15 / 10 / 24.85 \mathrm{~mL} \mathrm{~min}^{-1}$, 1 bar absolute pressure and $1.28 \mathrm{mg}$ of $\mathrm{Cu}$ loaded for each test. GHSV: $35000 \mathrm{~h}^{-1}$.

for more details on the carbon supported catalysts) and more specifically on the activated (reduced) $3 \mathrm{~nm}-\mathrm{Cu} / \mathrm{SiO}_{2}$ and $7 \mathrm{~nm} \_\mathrm{Cu} / \mathrm{SiO}_{2}$ catalysts.

The stability of these two selected catalysts was investigated by means of isothermal runs. Selectivity to butenes and butenes composition are reported in Figure $\mathrm{S} 7$. The $3 \mathrm{~nm} \mathrm{Cu} /$ $\mathrm{SiO}_{2}$ sample tested at $130^{\circ} \mathrm{C}$ exhibited full conversion for the entire $60 \mathrm{~h}$ of catalytic test. At full conversion, it was not possible to observe small changes in activity. Long-term tests on the sample $7 \mathrm{~nm}-\mathrm{Cu} / \mathrm{SiO}_{2}\left(140{ }^{\circ} \mathrm{C}\right.$, otherwise same conditions) revealed a high stability, with the 1,3-butadiene conversion equal to $\sim 40 \%$ from the beginning to the end of the run. It is interesting to note a good agreement between these data and the one collected at steady-state conditions (Figure 4) for both the samples, which underlines the remarkable stability of these catalysts (in particular for the 7 $\mathrm{nm} \mathrm{Cu}$ on $\mathrm{SiO}_{2}$ ). Lastly, ex situ FT-IR investigations of the fresh and used samples revealed no significant oligomers/green oil formation (see Figure S8).

The catalysts described in this work were significantly more stable than $\mathrm{Cu}$ catalysts immobilized on other oxidic supports reported in the literature. A direct comparison between our systems and $5 \mathrm{~nm} \mathrm{Cu} / \mathrm{TiO}_{2}$ described by Wang et al. tested using the same reaction mixture, yet $T=90{ }^{\circ} \mathrm{C}$, shows that the $5 \mathrm{~nm} \mathrm{Cu} / \mathrm{TiO}_{2}$ catalyst lost all more than $90 \%$ activity after $<10 \mathrm{~h}$ on stream. ${ }^{35}$ Deactivation was mainly ascribed to significant "green oil" or coke poisoning (formation of $\mathrm{C}_{4+}$ oligomers or carbonaceous deposit)..$^{6,29,35}$ No results for $\mathrm{Cu}$ catalysts on $\mathrm{SiO}_{2}$ have been reported previously; however, differences in stability between $\mathrm{SiO}_{2}$ - and $\mathrm{TiO}_{2}$ - supported catalysts were reported by our group for Au-based systems used in selective hydrogenation for the same reaction mixture. ${ }^{37}$ Higher stability was observed for Au nanoparticles immobilized on the silica support than on titania P25 (almost full retention of the activity for $\mathrm{Au} / \mathrm{SiO}_{2}$ catalyst after $16 \mathrm{~h}$ at $200{ }^{\circ} \mathrm{C}$, versus $88 \%$ loss in activity for $\mathrm{Au} / \mathrm{TiO}_{2}$ tested in the same conditions). Also in this case, used catalyst characterization revealed important coke formation for the sample $\mathrm{Au}$ / $\mathrm{TiO}_{2}{ }^{37}$ An important role of the support was reported for the hydrogenation of alkynes as well. Sárkány, ${ }^{47}$ for instance, observed that the amount of carbon deposited over Pd catalyst 
supported on $\mathrm{TiO}_{2}$ was twice the one on $\alpha-\mathrm{Al}_{2} \mathrm{O}_{3}$ during pulseflow hydrogenation experiment of ethyne/ethene mixtures (3.9 carbon atoms per $\mathrm{Pd}$ surface atom for $\mathrm{Pd} / \mathrm{TiO}_{2}$ versus 1.66 for $\left.\mathrm{Pd} / \mathrm{Al}_{2} \mathrm{O}_{3}\right)$. Combination of adjacent vinyl species and/or insertion of ethyne into $\mathrm{Pd}-\mathrm{C}$ bond of adsorbed vinyl intermediates to form a diene were considered to be the initiator of the formation of green oil in ethyne hydrogenation. The authors postulated that the $\mathrm{TiO}_{2}$ support, due to the presence of $\mathrm{Ti}^{3+}$ sites decorating the Pd particle, enhanced the concentration of retained hydrocarbons over the surface of the catalyst, leading to a greater formation of $\mathrm{C}_{6+}$ oligomers. ${ }^{47} \mathrm{It}$ is clear that using more inert supports, as we show here for $\mathrm{Cu}$ based catalysts, is a successful strategy to produce stable catalysts for the hydrogenation of alkadienes.

Selectivity. In this section, the selectivities of $3 \mathrm{~nm} \mathrm{Cu} /$ $\mathrm{SiO}_{2}$ and $7 \mathrm{~nm} \_\mathrm{Cu} / \mathrm{SiO}_{2}$ are discussed in more detail, based on the data from Figure 4. Selectivities are reported in terms of both the evolution of the propene conversion (Figure 6A) and
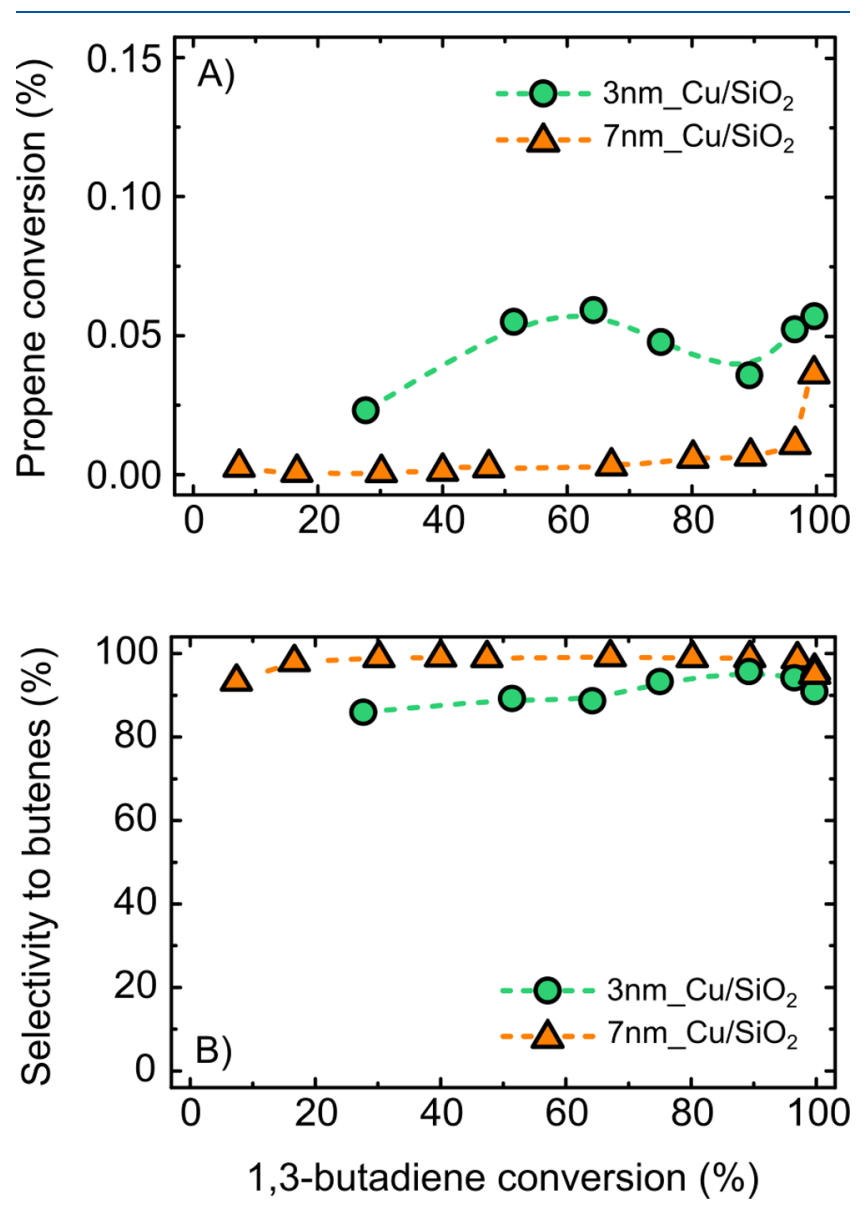

Figure 6. (A) Propene conversion and (B) selectivity to butenes data (defined as the ratio between the butenes productivity over the total hydrogen consumption) as a function of the 1,3-butadiene conversion for the reduced $3 \mathrm{~nm} \_\mathrm{Cu} / \mathrm{SiO}_{2}$ and $7 \mathrm{~nm} \_\mathrm{Cu} / \mathrm{SiO}_{2}$. Pretreatment, reaction conditions, and testing methodology are as in Figure 4.

the selectivity to butenes (defined as the ratio between the $\mathrm{C}_{4}$ alkenes productivity over the total hydrogen consumption; see section 4 of the Supporting Information) (Figure 6B) as a function of the 1,3-butadiene conversion. Hydrogenation of alkenes to alkanes was limited, with a propene conversion below $0.1 \%$ in the entire 1,3 -butadiene conversion range (Figure 6A). Sample 3nm_Cu/SiO 2 exhibited a maximal alkene conversion of $0.06 \%$, while for $7 \mathrm{~nm} \mathrm{Cu} / \mathrm{SiO}_{2}$ the hydrogenation of propene was equal to $0.013 \%$ at almost full (97\%) 1,3-butadiene conversion (corresponding to roughly 40 ppm of propane present in the reactor outlet stream).

Although the propene conversion is commonly used in the literature to assess the performance of this class of hydrogenation catalysts, it is valuable to additionally look at the total selectivity to butenes (Figure 6B). In this way both undesired reactions, hydrogenation of propene and over-hydrogenation of 1,3-butadiene, can be taken into consideration. Both silica supported catalysts presented high selectivity. For instance, at 97\% 1,3-butadiene conversion, the selectivities to butenes were 94\% for the $3 \mathrm{~nm} \mathrm{Cu}$ and an astonishing 99\% to butenes for $7 \mathrm{~nm} \_\mathrm{Cu} / \mathrm{SiO}_{2}$. It is interesting to appreciate the substantial difference in selectivity between the two catalysts. The higher overall activity of $3 \mathrm{~nm} \_\mathrm{Cu} / \mathrm{SiO}_{2}$ in terms of 1,3-butadiene hydrogenation to butenes (Figure 4B) and alkenes hydrogenation with respect to $7 \mathrm{~nm} \_\mathrm{Cu} / \mathrm{SiO}_{2}$ (Figure 6) suggests a possible particle size effect. $\bar{T}$ his aspect will be covered in further studies.

To better understand the catalyst selectivity, sample $3 \mathrm{~nm} \_\mathrm{Cu} / \mathrm{SiO}_{2}$ was also tested at temperatures well above $140{ }^{\circ} \mathrm{C}$, the $\mathrm{T}$ required to achieve full hydrogenation of $1,3-$ butadiene. Under these conditions (with top-down flow) at the bottom of the catalytic bed, the 1,3-butadiene concentration is negligible, and the reaction atmosphere consists mainly of propene, butenes, and $\mathrm{H}_{2}$. The fraction of the catalytic bed that experiences these conditions increases with the reaction temperature. The 1,3-butadiene conversion, propene conversion, and $\mathrm{C}_{4}$ composition are reported in Figure 7 . The

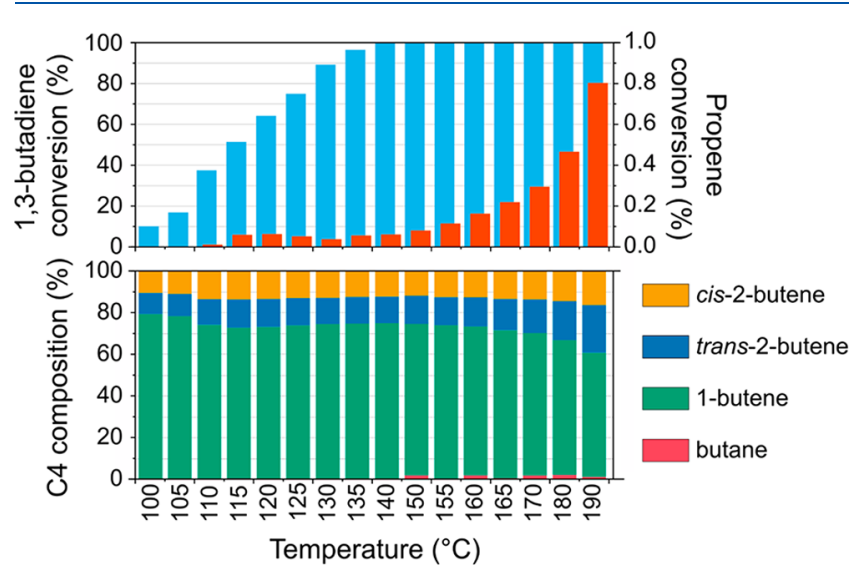

Figure 7. 1,3-Butadiene conversion (blue bars), propene conversion (orange bars), and $\mathrm{C}_{4}$ (butenes) distribution as a function of temperature for $3 \mathrm{~nm} \_\mathrm{Cu} / \mathrm{SiO}_{2}$. Pretreatment, reaction conditions, and testing methodology are as in Figure 4.

propene conversion is low and constant from $110{ }^{\circ} \mathrm{C}$ up to 150 ${ }^{\circ} \mathrm{C}$ (temperatures at which the 1,3-butadiene consumption is below 98\%). At temperatures higher than $140{ }^{\circ} \mathrm{C}$, i.e., at full conversion, when the concentration of 1,3-butadiene is depleted in the bottom of the catalytic bed, the propene conversion increases (even though remains lower than $1 \%$ at $50{ }^{\circ} \mathrm{C}$ higher than the temperature required for full 1,3butadiene hydrogenation).

A similar trend was observed for the $C_{4}$ products, with the trans-2-butene concentration increasing with temperature only above $150{ }^{\circ} \mathrm{C}$, at the expense of the less stable 1-butene, a sign that isomerization becomes significant only when $100 \%$ 
conversion is reached and when part of the catalytic bed is depleted in 1,3-butadiene (see Figure S9 for butenes thermodynamic data). Concomitantly, $n$-butane appears as a product of the hydrogenation of $\mathrm{C}_{4}$ species from $150{ }^{\circ} \mathrm{C}$ onward. This clearly suggests that competitive adsorption, hence the strong adsorption of 1,3-butadiene on $\mathrm{Cu}$, is a key factor in the catalyst high selectivity for alkadiene conversion, as side reactions such as isomerization or further hydrogenation of alkenes only take place once the 1,3-butadiene concentration is severely depleted in the reactor and hence also low in concentration at the surface of the $\mathrm{Cu}$ particles. This can be compared to what was observed for the palladium-based catalysts for which the preferential adsorption of alkynes and dienes makes it possible to maintain high alkenes selectivity up to relatively high conversion, although the hydrogenation rate of adsorbed ethene is for instance about 100 times higher than that of adsorbed ethyne. ${ }^{48,49}$

Further evidence is provided by analyzing the reaction kinetics data. From the study of the 1,3-butadiene hydrogenation rate as a function of the partial pressure of the reactive species (details in Figure S10), we observed a firstorder dependency in $\mathrm{H}_{2}$ pressure, a fractional positive order in 1,3 -butadiene $(0.25)$ and a nearly zeroth order in propene (0.08). The first-order dependency in hydrogen pressure suggests a low hydrogen surface coverage (linear adsorption regime), ${ }^{1,31}$ in line with the general observation that $\mathrm{H}_{2}$ adsorbs relatively weakly on $\mathrm{Cu}{ }^{1,30}$ The only slightly positive order in 1,3-butadiene can be ascribed to its particularly strong affinity to bind the copper nanoparticles, since almost complete surface saturation is reached. The low reaction order in 1,3-butadiene is in line with literature reports for experiments involving $\mathrm{Ni}, \mathrm{Au}, \mathrm{Pd}$, and Co. ${ }^{1,18,31,50}$ In addition, this kinetic behavior partially resembles what was observed in the case of $\mathrm{Pd}$ model catalysts $\left(\mathrm{Pd} / \mathrm{Al}_{2} \mathrm{O}_{3} / \mathrm{NiAl}(110), \mathrm{Pd}>4\right.$ $\mathrm{nm}),{ }^{18}$ for which the 1,3 -butadiene adsorption can be so strong that the hydrocarbon can even limit hydrogen penetrating the adsorption layer and adsorbing onto Pd active sites. ${ }^{18}$ Lastly, the near-zeroth reaction order in propene partial pressure shows that the competition of adsorption between the butadiene and propene is strongly in favor of the former.

We hence explain the almost full selectivity to butenes of our $\mathrm{Cu} / \mathrm{SiO}_{2}$ system (Figure 6) to the strong preferential bonding of polyunsaturated molecules over monounsaturated ones. As long as there is an appreciable 1,3-butadiene concentration, the diene almost fully covers the surface of the $\mathrm{Cu}$ catalyst, hindering the hydrogenation and/or isomerization of alkenes (Figure 7). Interestingly, by assuming similar intrinsic hydrogenation rates for all the adsorbed hydrocarbons, the selectivity measured for $7 \mathrm{~nm} \_\mathrm{Cu} / \mathrm{SiO}_{2}$ at $130{ }^{\circ} \mathrm{C}$ would correspond to a 1,3-butadiene to propene surface coverage ratio of 50:1. Conversion of butenes (mainly 1-butene) was also very limited, which indicates that they (mainly 1-butene), once formed, then rapidly desorb from the surface of the copper nanoparticles. An adsorption/desorption-driven selectivity was already predicted computationally in the case of hydrogenation of alkynes/alkenes mixtures, such as ethyne/ ethene, ${ }^{36}$ propyne/propene over $\mathrm{Cu}$ and $\mathrm{Ni}^{51}$ and the hydrogenation of enynes over $\mathrm{Cu}^{52}$ In a recent study of the selective hydrogenation of 1-phenyl-1-propyne in a batch reactor, the authors found that $\mathrm{Cu} / \mathrm{SiO}_{2}$ has no intrinsic selectivity toward alkenes formation at full conversion since the apparent rate of hydrogenation of the alkene to the alkane is faster than that of hydrogenation of the alkyne to the alkene. ${ }^{53}$
They rather assigned the high selectivity to alkenes to a competitive substrate adsorption on the $\mathrm{Cu}$ nanoparticles with the adsorption constant of the alkyne on $\mathrm{Cu} / \mathrm{SiO}_{2}$ being orders of magnitude higher than that of the alkene.

Lastly, a comparison with the literature reveals that the propene conversion values here obtained (Figure 6A) are drastically lower than that for other $\mathrm{Cu}$-based catalysts in the literature $(0.1-1 \%)$, as measured under similar reaction conditions $\left(\mathrm{Cu} / \mathrm{TiO}_{2},{ }^{46} \mathrm{Cu}-\mathrm{Zn} / \mathrm{TiO}_{2},{ }^{35} \mathrm{Cu}-\mathrm{Au} / \mathrm{TiO}_{2}\right.$, and $\left.\mathrm{Au} / \mathrm{TiO}_{2}{ }^{6}\right)$. Our $\mathrm{Cu} / \mathrm{SiO}_{2}$ systems also outperform Pd-based NPs (generally $>1 \%$ propene conversion, same conditions), ${ }^{54}$ single-atom $\mathrm{Pd}$ and $\mathrm{Pt} / \mathrm{Cu}(\sim 0.1$ and $\sim 1 \%$ propene conversion; corresponding gas feed: $1.9 / 2 \%$ butadiene, $70 /$ $20 \%$ propene, $4.7 / 16 \%$ hydrogen and balance $\mathrm{He}$, respectively), ${ }^{55,56} \mathrm{Au} / \mathrm{SiO}_{2}$ catalysts (for which the conversion of propene was already particularly low, $<0.1 \%$, same conditions), ${ }^{37,40}$ or $\mathrm{PdAu}$ bimetallic nanorods (selectivity to butenes below $90 \%$, same conditions). ${ }^{54}$ To the best of our knowledge the highest butenes selectivity (>98\%) under similar conditions was reported for Cu-based catalysts obtained via carbonization of MOFs (HKUST-1, $50 \mathrm{wt} \% \mathrm{Cu}$ ). ${ }^{57}$

\section{CONCLUSIONS}

Copper nanoparticles $(\sim 3$ and $\sim 7 \mathrm{~nm})$ supported either on silica gel or on surface-oxidized graphitic carbon were synthesized and used as catalysts for the selective hydrogenation of 1,3-butadiene in the presence of a 100-fold excess of propene. A new protocol for the measurement of catalytic data for $\mathrm{Cu}$-based hydrogenation catalysts was developed, which is a more reliable alternative to the ramp-up methodology. The catalysts exhibited full conversion of the alkadiene at mild temperatures $\left(130-170{ }^{\circ} \mathrm{C}\right)$. The conversion of propene at almost full 1,3-butadiene consumption was generally less than $0.2 \%\left(0.01 \%\right.$ for the $7 \mathrm{~nm} \mathrm{Cu}$ on $\mathrm{SiO}_{2}$ system), and the selectivity to butenes was above $94 \%$ for all the catalysts (up to $99 \%$ for the same catalyst $7 \mathrm{~nm} \_\mathrm{Cu} / \mathrm{SiO}_{2}$ ). Reaction order and detailed product analysis proved that the exceptionally high selectivity can be ascribed to the strong preferential adsorption on the $\mathrm{Cu}$ surface of alkadienes rather than alkenes. Furthermore, the $7 \mathrm{~nm} \mathrm{Cu} / \mathrm{SiO}_{2}$ retained its initial activity for the full $60 \mathrm{~h}$ time on stream test at $140{ }^{\circ} \mathrm{C}$.

\section{ASSOCIATED CONTENT}

\section{SI Supporting Information}

The Supporting Information is available free of charge at https://pubs.acs.org/doi/10.1021/acs.jpcc.0c08077.

Materials, numerical check for mass and heat transport limitations, $\mathrm{C}_{4}$ products distribution measured during temperature ramp experiments, $\mathrm{H}_{2}$-TPR of the prepared samples, catalyst stability during steady-state experiments, transmission electron micrographs of fresh and used catalysts, stability measurements for $\mathrm{Cu} / \mathrm{C}$ samples, selectivity to butenes during stability tests, ex situ FT-IR collected for fresh and used $3 \mathrm{~nm} \mathrm{Cu}$ on $\mathrm{SiO}_{2}, \mathrm{C}_{4}$ alkenes equilibrium composition, reaction rate order analysis, TOF, and selectivity to butenes calculations (PDF)

\section{AUTHOR INFORMATION}

\section{Corresponding Author}

Petra E. de Jongh - Inorganic Chemistry and Catalysis, Debye Institute for Nanomaterials Science, Utrecht University, 
Utrecht, The Netherlands; 10 orcid.org/0000-0002-22162620; Email: P.E.deJongh@uu.nl

\section{Authors}

Giorgio Totarella - Inorganic Chemistry and Catalysis, Debye Institute for Nanomaterials Science, Utrecht University, Utrecht, The Netherlands

Rolf Beerthuis - Inorganic Chemistry and Catalysis, Debye Institute for Nanomaterials Science, Utrecht University, Utrecht, The Netherlands

Nazila Masoud - Biobased Chemistry and Technology, Wageningen University \& Research, Wageningen, The Netherlands; (1) orcid.org/0000-0001-7216-4133

Catherine Louis - Sorbonne Université, CNRS, Laboratoire de Réactivité de Surface (LRS), F-75005 Paris, France

Laurent Delannoy - Sorbonne Université, CNRS, Laboratoire de Réactivité de Surface (LRS), F-75005 Paris, France

Complete contact information is available at:

https://pubs.acs.org/10.1021/acs.jpcc.0c08077

\section{Author Contributions}

G.T. and R.B. contributed equally to this work. G.T., R.B., P.E.d.J., and L.D. designed the experiments. R.B. synthesized and characterized the functionalized carbon support and the Csupported $\mathrm{CuO}$ nanoparticles. G.T. synthesized and characterized the $\mathrm{SiO}_{2}$-supported $\mathrm{CuO}$ nanoparticles. G.T. and R.B. performed the catalytic experiments and analyzed the data. G.T. and P.E.d.J. wrote the paper. P.E.d.J. conceived and supervised the project. All authors discussed the results and edited the manuscript.

\section{Funding}

G.T. and P.E.d.J. were funded by NWO Vici project 16.130.344 and ERC-2014-CoG-648991. R.B. was funded by BP plc.

\section{Notes}

The authors declare no competing financial interest.

\section{ACKNOWLEDGMENTS}

The authors gratefully acknowledge NWO (NWO Vici 16.130.344), the European Research Council (ERC-2014CoG-648991), and BP plc for overall funding and support. The authors also gratefully acknowledge Dr. Baira Donoeva for the fruitful scientific discussions, Krijn de Jong and Glenn Sunley for stimulating conversations, and Jan Willem de Rijk for technical assistance with the 1,3-butadiene hydrogenation catalytic setup. Nynke Krans is acknowledged for high-angle annular dark-field STEM and bright-field TEM measurements.

\section{REFERENCES}

(1) Bond, G. C. Metal-Catalysed Reactions of Hydrocarbons; Springer: New York, 2005; Vol. 1.

(2) Veldsink, J. W.; Bouma, M. J.; Schöön, N. H.; Beenackers, A. A. C. M. Heterogeneous Hydrogenation of Vegetable Oils: A Literature Review. Catal. Rev.: Sci. Eng. 1997, 39, 253-318.

(3) Chen, B.; Dingerdissen, U.; Krauter, J. G. E.; Lansink Rotgerink, H. G. J.; Möbus, K.; Ostgard, D. J.; Panster, P.; Riermeier, T. H.; Seebald, S.; Tacke, T.; et al. New Developments in Hydrogenation Catalysis Particularly in Synthesis of Fine and Intermediate Chemicals. Appl. Catal., A 2005, 280, 17-46.

(4) Bonrath, W.; Medlock, J.; Schutz, J.; Wustenberg, B.; Netscher, T. In Hydrogenation; Karamé, I., Ed.; IntechOpen: Rijeka, Croatia, 2012; Vol. 1, pp 69-90.

(5) Blaser, H.-U.; Malan, C.; Pugin, B.; Spindler, F.; Steiner, H.; Studer, M. Selective Hydrogenation for Fine Chemicals: Recent
Trends and New Developments. Adv. Synth. Catal. 2003, 345, 103151.

(6) Delannoy, L.; Thrimurthulu, G.; Reddy, P. S.; Méthivier, C.; Nelayah, J.; Reddy, B. M.; Ricolleau, C.; Louis, C. Selective Hydrogenation of Butadiene over $\mathrm{TiO}_{2}$ Supported Copper, Gold and Gold-Copper Catalysts Prepared by Deposition-Precipitation. Phys. Chem. Chem. Phys. 2014, 16, 26514-26527.

(7) Nikolaev, S. A.; Zanaveskin, L. N.; Smirnov, V. V.; Averyanov, V. A.; Zanaveskin, K. L. Catalytic Hydrogenation of Alkyne and Alkadiene Impurities from Alkenes. Practical and Theoretical Aspects. Russ. Chem. Rev. 2009, 78, 231-247.

(8) Koeppel, R. A.; Wehrli, J. T.; Wainwright, M. S.; Trimma, D. L.; Cant, N. W. Selective Hydrogenation of $\mathrm{C}_{4}$-Alkynes over a Copper on Silica Catalyst. Appl. Catal., A 1994, 120, 163-177.

(9) Ren, T.; Patel, M.; Blok, K. Olefins from Conventional and Heavy Feedstocks: Energy Use in Steam Cracking and Alternative Processes. Energy 2006, 31, 425-451.

(10) Červený, L. Catalytic Hydrogenation; Elsevier: Amsterdam, 1986.

(11) Bender, M. An Overview of Industrial Processes for the Production of Olefins - $\mathrm{C}_{4}$ Hydrocarbons. ChemBioEng. Rev. 2014, 1, 136-147.

(12) Che, C.; Liang, Y.; Qian, Y.; Han, W.; Zhang, F.; Gou, G.; Jing, X.; Chang, X.; Gui, Q.; Gu, L.; et al. Palladium-Based Supported Hydrogenation Catalyst, and Preparation Method and Application Thereof. U.S. Patent US 2018/0290949 A1, 2018.

(13) Borodziński, A.; Bond, G. C. Selective Hydrogenation of Ethyne in Ethene-Rich Streams on Palladium Catalysts, Part 2: Steady-State Kinetics and Effects of Palladium Particle Size, Carbon Monoxide, and Promoters. Catal. Rev.: Sci. Eng. 2008, 50, 379-469.

(14) Chinayon, S.; Mekasuwandumrong, O.; Praserthdam, P.; Panpranot, J. Selective Hydrogenation of Acetylene over Pd Catalysts Supported on Nanocrystalline $\alpha-\mathrm{Al}_{2} \mathrm{O}_{3}$ and $\mathrm{Zn}$-Modified $\alpha-\mathrm{Al}_{2} \mathrm{O}_{3}$. Catal. Commun. 2008, 9, 2297-2302.

(15) Ravanchi, M. T.; Sahebdelfar, S.; Fard, M. R.; Fadaeerayeni, S.; Bigdeli, P. Pd-Ag $/ \alpha-\mathrm{Al}_{2} \mathrm{O}_{3}$ Catalyst Deactivation in Acetylene Selective Hydrogenation Process. Chem. Eng. Technol. 2016, 39, 301-310.

(16) Piccolo, L.; Piednoir, A.; Bertolini, J. C. Pd-Au Single-Crystal Surfaces: Segregation Properties and Catalytic Activity in the Selective Hydrogenation of 1,3-Butadiene. Surf. Sci. 2005, 592, 169-181.

(17) Piccolo, L.; Valcarcel, A.; Bausach, M.; Thomazeau, C.; Uzio, D.; Berhault, G. Tuning the Shape of Nanoparticles to Control Their Catalytic Properties: Selective Hydrogenation of 1,3-Butadiene on $\mathrm{Pd} / \mathrm{Al}_{2} \mathrm{O}_{3}$. Phys. Chem. Chem. Phys. 2008, 10, 5504-5506.

(18) Silvestre-Albero, J.; Rupprechter, G.; Freund, H. J. Atmospheric Pressure Studies of Selective 1,3-Butadiene Hydrogenation on WellDefined $\mathrm{Pd} / \mathrm{Al}_{2} \mathrm{O}_{3} / \mathrm{NiAl}(110)$ Model Catalysts: Effect of Pd Particle Size. J. Catal. 2006, 240, 58-65.

(19) Vignola, E.; Steinmann, S. N.; Vandegehuchte, B. D.; Curulla, D.; Sautet, P. $\mathrm{C}_{2} \mathrm{H}_{2}$-Induced Surface Restructuring of Pd-Ag Catalysts: Insights from Theoretical Modeling. J. Phys. Chem. C 2016, 120, 26320-26327.

(20) Jin, Y.; Datye, A. K; Rightor, E.; Gulotty, R.; Waterman, W.; Smith, M.; Holbrook, M.; Maj, J.; Blackson, J. The Influence of Catalyst Restructuring on the Selective Hydrogenation of Acetylene to Ethylene. J. Catal. 2001, 203, 292-306.

(21) Furlong, B. K.; Hightower, J. W.; Chan, T. Y.-L.; Sarkany, A.; Guczi, L. 1,3-Butadiene Selective Hydrogenation Over Pd/Alumina and CuPd/Alumina Catalysts. Appl. Catal., A 1994, 117, 41-51.

(22) Hill, T.; Haake, M.; Schwab, E.; Frenzel, A.; Worz, H. Selective Catalytic Gas-Phase Hydrogenation of Alkynes, Dienes, Alkenynes and/or Polyenes. U.S. Patent US 2003/0069458 A1, 2003.

(23) Arganbright, R. P. Selective Hydrogenation of Dienes and Acetylenes in $\mathrm{C}_{3}$ Streams. WIPO Patent WO 94/04477, 1994.

(24) Putman, H. M.; Adams, J. R. Process and Catalyst for Selective Hydrogenation of Dienes and Acetylenes. U.S. Patent US 8,227,650 B2, 2012. 
(25) Sugeta, M.; Fukada, H. Catalyst for Selective Hydrogenation of Acetylene Compounds in 1,3- Butadiene, Method for Producing the Same and Method of Using the Same. E.P. Patent EP 2329879 A1, 2011

(26) Ryu, Y. J. Selective Hydrogenation Process and Catalyst. WIPO Patent WO 2006/044005 A2, 2006.

(27) Beerthuis, R.; Sunley, J. G.; De Jong, K.; De Jongh, P. Selective Hydrogenation of Polyunsaturates. WIPO Patent WO2019/233961, 2019.

(28) Nuss, P.; Eckelman, M. J. Life Cycle Assessment of Metals: A Scientific Synthesis. PLoS One 2014, 9, No. e101298.

(29) Wehrli, J. T.; Thomas, D. J.; Wainwright, M. S.; Trimm, D. L.; Cant, N. W. Selective Hydrogenation of Propyne over Supported Copper Catalysts: Influence of Support. Appl. Catal. 1991, 70, 253262.

(30) Nishimura, E.; Inoue, Y.; Yasumori, I. The Mechanism of the Selective Hydrogenation of 1,3-Butadiene on Copper Surfaces. Bull. Chem. Soc. Jpn. 1975, 48, 803-807.

(31) Phillipson, J. J.; Wells, P. B.; Wilson, G. R. The Hydrogenation of Alkadienes. Part III. The Hydrogenation of Buta-1,3-Diene Catalysed by Iron, Cobalt, Nickel, and Copper. J. Chem. Soc. A 1969, 1351-1363.

(32) Ossipoff, N. J.; Cant, N. W. The Hydrogenation and Oligomerization of Propyne over an Ion-Exchanged Copper on Silica Catalyst. J. Catal. 1994, 148, 125-133.

(33) Wehrli, J. T.; Thomas, D. J.; Wainwright, M. S.; Trimm, D. L.; Cant, N. W. Selective Hydrogenation of Propyne over an IonExchanged Copper on Silica Catalyst. Appl. Catal. 1990, 66, 199-208.

(34) Garcia Cervantes, G.; Cadete Santos Aires, F. J.; Bertolini, J. C. Compared Properties of Pd on Thermo-Conductor Supports ( $\mathrm{SiC}$, $\left.\mathrm{Si}_{3} \mathrm{~N}_{4}\right)$ and Pd on Oxide Supports $\left(\mathrm{Al}_{2} \mathrm{O}_{3}, \mathrm{SiO}_{2}\right)$ for the 1,3-Butadiene Hydrogenation Reaction. J. Catal. 2003, 214, 26-32.

(35) Wang, Z.; Wang, G.; Louis, C.; Delannoy, L. Novel Non-Noble Bimetallic $\mathrm{Cu}-\mathrm{Zn} / \mathrm{TiO}_{2}$ Catalysts for Selective Hydrogenation of Butadiene. J. Catal. 2017, 347, 185-196.

(36) Studt, F.; Abild-Pedersen, F.; Bligaard, T.; Sørensen, R. Z.; Christensen, C. H.; Nørskov, J. K. Identification of Non-Precious Metal Alloy Catalysts for Selective Hydrogenation of Acetylene. Science 2008, 320, 1320-1322.

(37) Masoud, N.; Delannoy, L.; Schaink, H.; van der Eerden, A.; de Rijk, J. W.; Silva, T. A. G.; Banerjee, D.; Meeldijk, J. D.; de Jong, K. P.; Louis, C.; et al. Superior Stability of $\mathrm{Au} / \mathrm{SiO}_{2}$ Compared to $\mathrm{Au} / \mathrm{TiO}_{2}$ Catalysts for the Selective Hydrogenation of Butadiene. ACS Catal. 2017, 7, 5594-5603.

(38) Munnik, P.; de Jongh, P. E.; de Jong, K. P. Recent Developments in the Synthesis of Supported Catalysts. Chem. Rev. 2015, 115, 6687-6718.

(39) Munnik, P.; Wolters, M.; Gabrielsson, A.; Pollington, S. D.; Headdock, G.; Bitter, J. H.; de Jongh, P. E.; de Jong, K. P. Copper Nitrate Redispersion to Arrive at Highly Active Silica-Supported Copper Catalysts. J. Phys. Chem. C 2011, 115, 14698-14706.

(40) Masoud, N.; Delannoy, L.; Calers, C.; Gallet, J. J.; Bournel, F.; de Jong, K. P.; Louis, C.; de Jongh, P. E. Silica-Supported Au-Ag Catalysts for the Selective Hydrogenation of Butadiene. ChemCatChem 2017, 9, 2418-2425.

(41) Beerthuis, R.; de Rijk, J. W.; Deeley, J. M. S.; Sunley, G. J.; de Jong, K. P.; de Jongh, P. E. Particle Size Effects in Copper-Catalyzed Hydrogenation of Ethyl Acetate. J. Catal. 2020, 388, 30-37.

(42) Wang, G.; van den Berg, R.; de Mello Donega, C.; de Jong, K. P.; de Jongh, P. E. Silica-Supported $\mathrm{Cu}_{2} \mathrm{O}$ Nanoparticles with Tunable Size for Sustainable Hydrogen Generation. Appl. Catal., B 2016, 192, 199-207.

(43) Briot, P.; Primet, M. Catalytic Oxidation of Methane over Palladium Supported on Alumina. Effect of Aging under Reactants. Appl. Catal. 1991, 68, 301-314.

(44) Yadav, O. P.; Palmqvist, A.; Cruise, N.; Holmberg, K. Synthesis of Platinum Nanoparticles in Microemulsions and Their Catalytic Activity for the Oxidation of Carbon Monoxide. Colloids Surf., A 2003, 221, 131-134.
(45) Hugon, A.; Delannoy, L.; Louis, C. Supported Gold Catalysts for Selective Hydrogenation of 1,3-Butadiene in the Presence of an Excess of Alkenes. Gold Bull. 2008, 41, 127-138.

(46) Wang, Z.; Brouri, D.; Casale, S.; Delannoy, L.; Louis, C. Exploration of the Preparation of $\mathrm{Cu} / \mathrm{TiO}_{2}$ Catalysts by DepositionPrecipitation with Urea for Selective Hydrogenation of Unsaturated Hydrocarbons. J. Catal. 2016, 340, 95-106.

(47) Sárkány, A. Formation of $\mathrm{C}_{4}$ Oligomers in Hydrogenation of Acetylene over $\mathrm{Pd} / \mathrm{Al}_{2} \mathrm{O}_{3}$ Catalysts. React. Kinet. Catal. Lett. 2001, 74, 299-307.

(48) Bond, G. C.; Wells, P. B. The Mechanism of the Hydrogenation of Unsaturated Hydrocarbons on Transition Metal Catalysts. Adv. Catal. 1965, 15, 91-226.

(49) Silvestre-Albero, J.; Rupprechter, G.; Freund, H. J. From Pd Nanoparticles to Single Crystals: 1,3-Butadiene Hydrogenation on Well-Defined Model Catalysts. Chem. Commun. 2006, 1, 80-82.

(50) Hugon, A.; Delannoy, L.; Louis, C. Influence of the Reactant Concentration in Selective Hydrogenation of 1,3-Butadiene over Supported Gold Catalysts under Alkene Rich Conditions: A Consideration of Reaction Mechanism. Gold Bull. 2009, 42, 310-320.

(51) Bridier, B.; López, N.; Pérez-Ramírez, J. Partial Hydrogenation of Propyne over Copper-Based Catalysts and Comparison with Nickel-Based Analogues. J. Catal. 2010, 269, 80-92.

(52) Bridier, B.; Karhánek, D.; Pérez-Ramírez, J.; López, N. Molecular Understanding of Enyne Hydrogenation over Palladium and Copper Catalysts. Chem CatChem 2012, 4, 1420-1427.

(53) Kaeffer, N.; Larmier, K.; Fedorov, A.; Copéret, C. Origin of Ligand-Driven Selectivity in Alkyne Semihydrogenation over SilicaSupported Copper Nanoparticles. J. Catal. 2018, 364, 437-445.

(54) van der Hoeven, J. E. S.; Jelic, J.; Olthof, L. A.; Totarella, G.; Studt, F.; van Blaaderen, A.; de Jongh, P. E. Unlocking Synergy in Bimetallic Catalysts by Core-Shell Design. ChemRxiv DOI: 10.26434/chemrxiv.13218155.v1 (accessed November 17, 2020).

(55) Yan, H.; Cheng, H.; Yi, H.; Lin, Y.; Yao, T.; Wang, C.; Li, J.; Wei, S.; Lu, J. Single-Atom $\mathrm{Pd}_{1} /$ Graphene Catalyst Achieved by Atomic Layer Deposition: Remarkable Performance in Selective Hydrogenation of 1,3-Butadiene. J. Am. Chem. Soc. 2015, 137, 10484-10487.

(56) Lucci, F. R.; Liu, J.; Marcinkowski, M. D.; Yang, M.; Allard, L. F.; Flytzani-Stephanopoulos, M.; Sykes, E. C. H. Selective Hydrogenation of 1,3-Butadiene on Platinum-Copper Alloys at the SingleAtom Limit. Nat. Commun. 2015, 6, 1-8.

(57) Hu, N.; Li, X.-Y.; Liu, S.-M.; Wang, Z.; He, X.-K.; Hou, Y.-X.; Wang, Y.-X.; Deng, Z.; Chen, L.-H.; Su, B.-L. Enhanced Stability of Highly-Dispersed Copper Catalyst Supported by Hierarchically Porous Carbon for Long Term Selective Hydrogenation. Chin. J. Catal. 2020, 41, 1081-1090.

\section{NOTE ADDED AFTER ASAP PUBLICATION}

This paper was published ASAP on December 23, 2020, prior to implementation of final figure and Supporting Information edits during production. The corrected version was posted December 28, 2020. 